\title{
Boyd Swinburn, a sindemia global e a classificação NOVA
}

\author{
Boyd Swinburn, the global syndemic and the \\ NOVA classification
}

\author{
Boyd Swinburn, la sindemia global y la \\ clasificación NOVA
}

doi: 10.1590/0102-311X00312520

João Peres 1

Victor Matioli 1

Boyd Swindurn 2

1 O Joio e o Trigo, São Paulo, Brasil.

2 School of Population Health, University

of Auckland, Auckland, New Zealand.

Correspondência

J. Peres

O Joio e o Trigo.

Rua Rocha 238, São Paulo, SP

01330-000, Brasil.

joaomdperes@gmail.com
Boyd Swinburn entende que as evidências em torno da classificação NOVA são cada vez mais volumosas, e é questão de tempo para que algumas resistências sejam superadas. O professor da Escola de Saúde da População da Universidade de Auckland, na Nova Zelândia, enxerga uma conexão clara entre a divisão dos alimentos por extensão e propósito de processamento, e o conceito de sindemia global, que analisa o encontro entre desnutrição, obesidade e mudanças climáticas. Swinburn coordenou o grupo de pesquisadores reunidos pela revista The Lancet ${ }^{1}$ para analisar as interações entre esses três fatores, que afetam a maioria das pessoas em todos os países e regiões do mundo. Elas constituem uma sindemia, ou sinergia de epidemias, porque coexistem no tempo e lugar, interagem entre si para produzir sequelas complexas e compartilham fatores sociais fundamentais comuns.

Em entrevista à CSP, o pesquisador avalia que há um claro papel dos alimentos ultraprocessados nessa sindemia. "Se você for além dessas manifestações visíveis da sindemia global e se perguntar 'o quê do sistema alimentar está levando a essas três coisas?', então você acaba chegando em 'o que está impulsionando toda a onda de alimentos ultraprocessados é como o sistema alimentar está configurado"'.

O professor afirma que a liderança do Brasil na elaboração de diretrizes alimentares é fundamental. Ele admira especialmente a abordagem holística do Guia Alimentar para a População Brasileira, publicado em 2014 pelo Ministério da Saúde. A conexão da alimentação com questões ambientais e processos históricos e culturais é vista como um ponto forte. Para ele, a NOVA ainda guarda um "sabor latino-americano", no sentido de que vai lentamente sendo incorporada por outros grupos de pesquisa ao redor do mundo. 


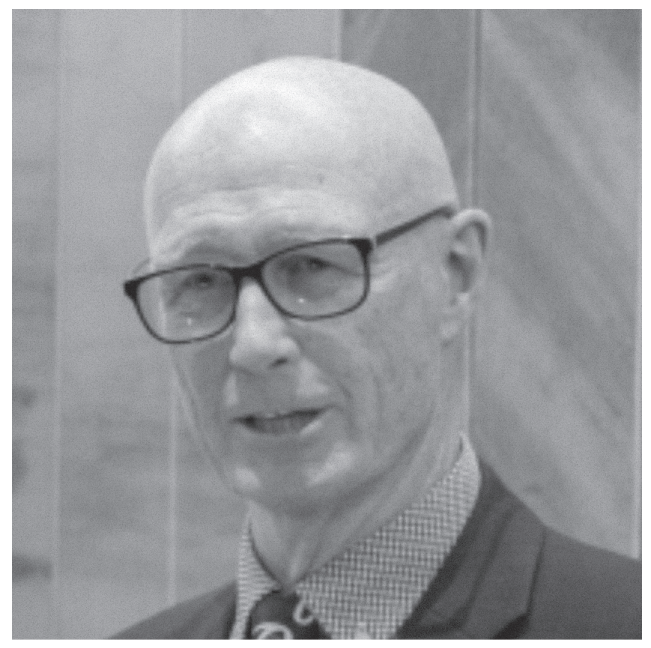

Dr. Boyd Swinburn (foto: Universidade de Auckland).

João Como você avalia a classificação NOVA? Como você avalia isso tudo? O que você acha que são seus avanços e quais são seus pontos fracos?

Boyd Bem, o seu ponto fraco é que é algo novo, então leva tempo para as pessoas se acostumarem. As pessoas tendem a reagir contra coisas novas, afinal. Ela constitui uma grande ameaça aos grandes fabricantes de alimentos, portanto há bastante resistência contra ela politicamente. Eles não querem ver que o que eles fazem é fundamentalmente prejudicial à saúde, daí essa resistência. Como com qualquer classificação, não exclusivamente da NOVA, há problemas mais periféricos para se lidar nos quais você pode adicionar um pouquinho disto a um iogurte, e ele deixa de ser um alimento processado saudável e se torna um alimento ultraprocessado que faz mal para você. Mas isso vale para tudo, para os Health Star Ratings, qualquer coisa. Ao meu ver estes são seus principais pontos fracos. É uma fraqueza em potencial, uma vez que não há um entendimento mecanístico claro sobre como isto afetará a saúde. Isso é particularmente desafiador para pessoas que tendem a pensar por meio de processos lineares de uma relação só. Que o sal aumenta a pressão sanguínea, que isso gera risco de derrame e por aí vai, esse tipo de mecanismo é relativamente fácil de entender. Mas mesmo as pessoas do meio acadêmico ainda vêem o mecanismo como intrínseco do produto. Em outras palavras, os componentes do produto ao invés do panorama geral da comida ultraprocessada, ou seja, sua hiper palatabilidade, o fato de que se come mais rápido, o fato de que tem bastante marketing por trás, que está disponível em todo lugar, que é de alto lucro, que tem longo prazo de vencimento, este tipo de coisa está sempre por aí. Há todo um conjunto de potenciais razões, não só biológicas, mas psicológicas, sociais e econômicas para o por quê isso pode levar ao sobreconsumo e obesidade e doenças não transmissíveis. Então eu acho que as pessoas têm dificuldades em entender isso.

Acho que as vantagens da classificação são o fato de ter uma boa quantidade de dados a respeito 2. $\mathrm{E}$ os dados incluem ensaios clínicos randomizados. Então, os dados também mostram que o impacto dos alimentos ultraprocessados vai além dos componentes de nutrientes que são fáceis de medir, como sal, açúcar, gorduras saturadas e assim por diante. E então o ensaio clínico randomizado tentou buscar estes nutrientes. Estudos epidemiológicos muitas vezes tentam ajustar-se a esses nutrientes para ver se é aí que está seu efeito. De qualquer maneira está bem claro para mim que a parte dos mecanismos envolvendo nutrientes é apenas uma parte disso tudo. Tem bastante coisa envolvida, muitos efeitos que não entendemos de verdade. Então, sabe, eu acho que as evidências estão realmente 
do lado da classificação, e estão aumentando rapidamente. Acho que a equipe refinou essas definições, então elas são fáceis de entender, um pouco mais claras.

Também acho que isso torna as coisas relativamente mais fáceis de serem comunicadas, de certo modo. Que comida ultraprocessada é algo que você não prepararia na sua cozinha. Se você for checar os ingredientes e encontrar algo que você não reconhece, então provavelmente é ultraprocessado. Então, de certa forma, é um sistema de comunicação pública muito bom para se adquirir informação. E eu penso que isso meio que refina e valida o que muitas pessoas já pensam, isto é, que comidas processadas são um problema. E isso acaba definindo mais firmemente o que as pessoas pensam quando se trata de alimentos processados. É como se agregasse valor científico e especificidade a uma ideia que as pessoas já têm. Além disso, durante a medição e monitoramento, estávamos fazendo alguns trabalhos de monitoramento de lojas e coisas no Peru, as chamadas "bodegas" e outros pontos de venda de alimentos. É bem fácil contar a proporção de alimentos ultraprocessados em uma loja. Você só enfia a cabeça e olha ao redor e você vê que $90 \%$ de tudo vem numa embalagem elegante, e o mais provável é que serão alimentos ultraprocessados. Você não precisa checar todo o teor de sódio, teor de gordura e açúcar e assim por diante. Então, para monitorar, as coisas ficam mais fáceis. E há várias vantagens nisso. Isso ainda é uma ocorrência mais sul-americano e não internacional, então o fato de que a Organização Pan-Americana da Saúde (OPAS) simplesmente pegou para usar, diferentemente de outros escritórios regionais da Organização Mundial da Saúde (OMS) que não o fizeram, dá a isso um sabor sul-americano. Mas há campeões internacionalmente, e todos esses estudos estão saindo internacionalmente, então acho que isso vai mudar com o tempo.

Victor Eu gostaria de saber se a NOVA se encaixa de alguma forma em sua agenda de pesquisa. E o que acha do termo "comida ultraprocessada"? Ele costuma ser usado pela sua comunidade de pesquisa?

Boyd Se eu já fiz pesquisas sobre alimentos ultraprocessados? Sim, fizemos um estudo observando os alimentos ultraprocessados em todo o mundo usando um Euromonitor e as mudanças ao longo do tempo por cerca de 30 anos, 20 ou 30 anos ou algo assim, e comparamos com as trajetórias de obesidade 3 . Fizemos esse tipo de estudos ecológicos, como são chamados. Fazemos muitas coisas sobre rotulagem e composição de alimentos e marketing para crianças e coisas similares, então, quando estamos classificando alimentos, classificamos eles de diferentes maneiras. Classificamos de acordo com o Sistema de Perfil Nutricional da Nova Zelândia, e o da OMS, e o da NOVA, esse tipo de coisa, comparamos diferentes sistemas de classificação, você sabe. Fora da América Latina, eu diria que há certa dificuldade de o termo ultraprocessado se firmar como uma categoria. Eu revi, no meio de algumas análises globais do momento sobre alimentos e sistemas alimentares em um nível relativamente superficial, e alguns deles reconhecem a questão dos alimentos altamente processados. Mas eles não usam o termo "ultraprocessado", acho que por causa da polêmica e da reação que ele provoca. E isso não aconteceu em muitos países, em particular nos Estados Unidos, provavelmente, mas também na Europa, o termo ainda não se consolidou. Assim, eles estão um pouco cautelosos em fazer isso, mas eu os incentivo a usar o termo "ultraprocessado" porque define mais precisamente o produto do que o termo "altamente processado" ou "alimentos processados", que as pessoas, só para se referir àquela ideia que as pessoas têm na cabeça, que não está bem definida. Creio que esteja chegando lá nos documentos internacionais, mas ainda falta um tanto.

João Agora falando um pouco sobre a reação contra a NOVA. Já falamos de pontos fracos, mas como você avalia as críticas à NOVA?

Boyd Bem, parte disso vem de uma crítica puramente comercial. Trata-se de grandes empresas com enorme interesse investido em alimentos processados. E ter um invólucro, uma embalagem figurativa de "prejudicial à saúde" colocada em todos os alimentos que eles fornecem é algo que eles não gostam muito. E eles irão responder de forma bastante previsível e estereotipada. Isso é natural. As pessoas dentro da indústria também usam alguns desses pontos fracos. Eles dirão: "Bem, este produto aqui, você está dizendo: 'Este está ok, mas este não está', com esta simples mudança”. Então, eles mergulham nas minúcias. Eles falam sobre a falta de mecanismos, que não faz nenhum sentido real, não é lógico, e eles usam esses tipos de argumentos, fazendo esse jogo de incertezas e algumas das fraquezas do sistema NOVA, penso eu. Não vi nenhuma grande empresa reconhecer a literatura. Dizem que tudo é evidência epidemiológica. E essa é outra forma de as pessoas rejeitarem as evidências, dizendo: "é só epidemiológico". Então, eles colocam estudos transversais, estudos ecológicos, estudos de coorte, 
estudos ecológicos longitudinais, tudo na mesma cesta, e dizem: "Isso é apenas epidemiologia, isso é muito complicado e altamente sujeito a preconceitos". E sim, todo estudo epidemiológico tem seus vieses. Como qualquer estudo tem. Mas quando você coloca esses vários tipos de estudos juntos, com diferentes vieses, e um padrão consistente surge, para mim isso diz algo sobre a pergunta que você está fazendo. E é isso que estou vendo na literatura epidemiológica, então dizer "isso é apenas epidemiologia" é só outra maneira de descartar as diretrizes. Eles vão resistir, e vão resistir com força por muito tempo ainda. O que provavelmente é um bom sinal de que você está no caminho certo.

Victor Eu gostaria de perguntar a você sobre as diretrizes alimentares brasileiras. Quando você analisa essas diretrizes como um todo, você acha que este tipo de documento contribui para essa mudança de paradigma de que maneira, além da adoção da NOVA?

Boyd Bem, essas diretrizes certamente contribuem, e de fato mudar para diretrizes alimentares sustentáveis é um passo extremamente concreto e factível para tentar transferir o paradigma para sistemas alimentares saudáveis e sustentáveis. Sistemas alimentares saudáveis e sustentáveis são uma ideia grande e nebulosa, muito complexa, muito detalhada, esse tipo de coisa. E as pessoas dizem: “Bem, o que você vai fazer amanhã?", e ok, diretrizes alimentares baseadas em alimentos sustentáveis são um passo muito concreto a se dar, e embora por um lado você possa dizer que as pessoas não prestam atenção, você sabe, o público em geral não presta atenção às diretrizes alimentares para guiar suas escolhas alimentares, e no entanto é uma plataforma muito poderosa, uma plataforma de políticas da qual outras coisas podem surgir. A merenda escolar, ou compras e aquisição, ou rotulagem por exemplo, há várias coisas que originam daí. Vejo diretrizes alimentares sustentáveis como um passo valioso e fundamentalmente concreto ao qual os países devem recorrer, e se todos os países seguissem esses passos, este tipo de discussão seria feita no dia a dia. Todo mundo estaria falando sobre isso em vários países com boas diretrizes alimentares sustentáveis no final das contas. No momento, por exemplo, os Estados Unidos estão revisando suas diretrizes alimentares e a sustentabilidade está completamente fora de questão. Ninguém tem permissão para falar sobre isso. Deste modo, no futuro, isso será totalmente inaceitável. Mas não chegamos lá ainda.

Quando estive na Austrália vários anos atrás, eles fizeram a mesma coisa, e a sustentabilidade foi jogada fora pela pressão da indústria. Então, estamos tendo que mudar para uma nova norma sobre o que é apropriado para as diretrizes alimentares e, hoje em dia, especialmente para os países ocidentais, conforme as diretrizes dietéticas são revisadas, é difícil ver como a sustentabilidade não seria elevada e colocada na mesa novamente 4 . Se é permitido permanecer na mesa, e se, você sabe, a pressão da indústria de alimentos vai tirá-lo da mesa é outra coisa, mas se um país como, eu não sei, a Bélgica ou Alemanha ou algo assim fosse rever suas diretrizes alimentares, seria difícil ver como isso não incluiria a sustentabilidade.

Então a liderança do Brasil nisso tem sido absolutamente fundamental. Não é apenas a sustentabilidade que é nova nas diretrizes brasileiras, elas são muito mais holísticas, levam em consideração todos os aspectos sociais, históricos e culturais dos alimentos que a maioria das diretrizes alimentares não faz. Portanto, o Brasil está muito à frente. Existem alguns outros países menores que introduziram essas diretrizes. Mas é necessário países grandes como o Brasil. O Canadá fez isso, embora de uma forma não tão explícita e forte quanto o Brasil, mas quando se trata de países grandes como o Canadá, que as pessoas notam, ter mais alguns desses países realmente faria o globo girar. Mas não se engane, a liderança do Brasil nisso foi absolutamente fundamental.

Victor Você acha que a sustentabilidade é o principal aspecto das diretrizes brasileiras?

Boyd Não é o principal aspecto, mas atualmente há uma grande onda de pressão por coisas sustentáveis, por sustentabilidade, mudanças climáticas, ambientes alimentares e, se houver algum país, se há alguma onda que um país vai pegar para trazer e revisar suas diretrizes alimentares sob algum paradigma diferente, será a sustentabilidade que vai fazer as diretrizes entrarem em foco. Se eles adotarem uma classificação NOVA ou qualquer outra coisa para suas definições, eu suspeito que isso seja um pouco mais distante, mas ter a sustentabilidade como foco é fundamental.

João Vamos falar um pouco sobre a reformulação. Alguns setores da indústria têm adotado listas de ingredientes concisas, tentando eliminar aditivos e até incorporando o termo "alimentos minimamente processados”. Como você analisa este movimento? Será que é realmente uma mudança em direção a produtos mais saudáveis? 
Boyd Acho que ênfase demais está sendo colocada em uma reformulação que não é necessária. Existem alguns aspectos sobre a composição dos alimentos que são muito claros e exigem muito esforço e... gorduras trans, retirar as gorduras trans do sistema é um exemplo clássico disso. Como você sabe, não há necessidade de gorduras trans. Muitos países o fizeram. Remover gorduras trans do sistema, da comida, é inequivocamente bom, simples e importante. O sal é a próxima reformulação provável. Algo que possui histórico mais longo. E eu acho que há um valor considerável em uma abordagem combinada. Mas é trabalho pesado. É um grande esforço organizado para reduzir o sal em alimentos ultraprocessados. São vários anos. O único exemplo realmente bom que temos é o Reino Unido, e foram muitos anos de esforço organizado, mas acho que se os governos adotassem isso e houvesse mais envolvimento do governo do que no Reino Unido, isso poderia ter um bom valor. Então, reformulação para gorduras trans, sim, definitivamente. Sal, sim, acho que tem muito valor. $\mathrm{O}$ açúcar é especialmente muito mais problemático. Muito mais. Temos a experiência da Agência de Saúde Pública da Inglaterra ${ }^{5}$ de uma reformulação estruturada, em que o governo está tentando, de forma voluntária, persuadir a indústria de alimentos a reduzir o teor de açúcar. E eles pretendiam obter uma redução de $20 \%$ até 2020 , e eles conseguiram $2 \%$. Não vai atingir a meta e, na verdade, está se tornando muito difícil. Mas muitas empresas, quando reformulam o açúcar, colocam adoçantes não nutritivos, de forma a manter o mesmo tipo de sabor doce. Você está perdendo um pouco do doce, algumas calorias de açúcar, mas não é realmente um grande avanço. Ainda tem alta doçura e as coisas continuam assim. E depois, além disso, em relação a todos os outros aditivos, adição de fibra, redução de corantes e aromatizantes e por aí vai. Sim, acho que tudo isso é bom, mas não vejo como uma estratégia séria que vai realmente mudar a salubridade da alimentação e da dieta, com exceção das gorduras trans e do sal. Já com o açúcar, acho que existem outras estratégias para alcançar sua reformulação, como os impostos que são provavelmente uma forma muito mais potente de fazer com que as empresas respondam.

Victor Vamos falar um pouco sobre as relações entre a sindemia global e a NOVA. Você enxerga um diálogo entre a teoria dos ambientes obesogênicos 6 , o conceito de sindemia global, e a classificação NOVA?

Boyd Sim, enxergo, eles dialogam em um nível bastante profundo. Vejo no nível da manifestação visível, onde você tem obesidade, desnutrição e mudanças climáticas. É muito fácil ver como isso dialoga com a obesidade. Isso é claríssimo, e as evidências estão ficando mais fortes. Quanto ao modo como isso dialoga com a subnutrição, acho que há uma história a respeito, e algumas evidências sobre como esses produtos estão chegando e são muito atraentes, e são muito saborosos, e isso leva a uma transição alimentar ocorrendo em muitos países de um tipo básico de dieta em direção a não uma grande variedade de produtos saudáveis, mas para produtos não saudáveis. Em outras palavras, eles estão começando a predominar de forma que os países, que as populações estão saindo dessa variedade de alimentos mais básicos e de subsistência possam mudar para uma dieta de maior variedade, o que é realmente melhor para sua saúde. Infelizmente, essa variedade está sendo direcionada para alimentos ultraprocessados apenas por causa desse domínio do mercado. Acho que está afetando a desnutrição, mas a narrativa tem um pouco mais de nuance. E em termos de mudanças climáticas, acho que no ponto de manifestação, digamos, qual é a contribuição dos alimentos ultraprocessados para o aumento dos gases do efeito estufa no sistema alimentar. E, na verdade, é bem pouco. É mais a produção, principalmente de carne bovina e laticínios, assim como desperdício de alimentos, porque agora os alimentos ultraprocessados permanecem por muito tempo. Eles não são desperdiçados. A embalagem pode ser, mas a comida em si não é. Portanto, alimentos ultraprocessados não figuram muito no nexo alimentos-mudança climática. Tem um papel secundário.

Se você for além dessas manifestações visíveis da sindemia global e se perguntar "o quê do sistema alimentar está levando a essas três coisas?", então você acaba chegando em "o que está impulsionando toda a onda de alimentos ultraprocessados é como o sistema alimentar está configurado". O modo como incentivamos e desincentivamos a indústria de alimentos, quais regras adotamos ou quais advertências. Como alertamos o público, coisas assim. Todas as políticas e economias e o tipo de expectativas em torno de normas e expectativas envolvendo alimentos e sistemas alimentares estabelecidas em um nível profundo, creio eu, estão criando alimentos ultraprocessados, por sua vez causando diabetes e doenças cardíacas e obesidade, que não é explicada por esse sistema alimentar. E o mesmo tipo de conjunto de mecanismos está permitindo que a produção de gado seja desenfreada 
e assim por diante. Então, sim, nos pontos de manifestação visíveis, você pode ver a história por trás, que é mais forte para alguns do que para outros. Mas em um nível mais profundo, é algo mais fundamental, trata-se da forma como construímos o sistema alimentar para começar.

João Sobre o Global Syndemic Report, você poderia identificar movimentos e reações de governos, setor privado, sociedade civil ou comunidade científica que incorporaram e tentaram dialogar e estabelecer novas propostas a partir do que foi proposto e detectado no Global Syndemic Report?

Boyd Estamos indo muito rapidamente em direção a sistemas alimentares sustentáveis, então, dentro do escopo do Global Syndemic Report, identificamos sistemas alimentares, sistemas de transporte, uso da terra e desenho urbano e, desses quatro, o que teve o maior impulso é o sistema alimentar, assim como sistemas alimentares sustentáveis. E eu acho que é onde haverá o maior impacto. Então, as reações existem e estão lá no meio do diálogo internacional. Este Global Syndemic Report foi publicado na mesma época que o EAT-Lancet Report 7 . O EAT-Lancet Report teve muitas críticas, especialmente da indústria de carnes e laticínios, e de pessoas que, bem, você sabe, o pessoal da "dieta paleo", que são como uma brigada a favor de dietas ricas em carboidratos e gorduras. E assim, houve bastante resistência, ao passo que o Global Syndemic Report não recebeu essa resistência. O apresentamos em vários países e me parece que ele ajuda as pessoas a unir essas coisas e ver, por meio dessas manifestações visíveis, as estruturas mais profundas do sistema alimentar que precisamos mudar. Então não vejo resistência internacional quanto a isso. E pode ser um conceito um pouco mais unificador do que o EAT-Lancet Report, que tendia a causar divisões. Mas os dois estão na mesa, os dois falam no mesmo sentido e, sim, acho que os dois pontos de vista são válidos e as pessoas certamente estão tendo a ideia de que essas coisas estão profundamente conectadas. 


\section{Colaboradores}

J. Peres e V. Matioli participaram da redação do texto e revisão da versão final a ser publicada. B. Swinburn revisou a versão final a ser publicada.

\section{Informações adicionais}

ORCID: João Peres (0000-0002-4767-2811); Victor Matioli (0000-0002-8961-5540); Boyd Swindurn (0000-0002-2131-045X).
1. Swinburn BA, Kraak VI, Allender S, Atkins VJ, Baker PI, Bogard JR, et al. The global syndemic of obesity, undernutrition, and climate change: the Lancet Commission Report. Lancet 2019; 393:791-846.

2. Monteiro CA, Cannon G, Lawrence M, Louzada MLC, Machado PP. Ultra-processed foods, diet quality, and health using the NOVA classification system. Rome: Food and Agriculture Organization; 2019.

3. Vandevijvere S, Jaacks L, Monteiro C, Monteiro A, Moubarac J-C, Girling-Butcher M, et al. Global trends in ultraprocessed food and drink product sales and their association with adult body mass index trajectories. Obes Rev 2019; 20 Suppl 2:10-9.

4. Fischer CG, Garnett T. Plates, pyramids, planet. Developments in national healthy and sustainable dietary guidelines: a state of play assessment. Rome: Food and Agriculture Organization/Oxford: Food Climate Research Network, University of Oxford; 2016;

5. Public Health England. Sugar reduction and wider reformulation programme. Report on progress towards the first 5\% reduction and next steps. London: Public Health England; 2018.

6. Swinburn B, Egger G, Raza F. Dissecting obesogenic environments: the development and application of a framework for identifying and prioritizing environmental interventions for obesity. Prev Med 1999; 29(6 Pt 1):563-70.

7. Willett W, Rockström J, Loken B, Springmann M, Lang T, Vermeulen S, et al. Food in the Anthropocene: the EAT-Lancet Commission on healthy diets from sustainable food systems. Lancet 2019; 393:447-92. 